\title{
Álcalis incorporados ao aluminato tricálcico: efeitos na hidratação
}

\author{
Alkalis incorporated into tricalcium aluminate: effects in \\ hydration
}

\author{
Ana Paula Kirchheim \\ Rui Barbosa de Souza \\ Denise Carpena Coitinho Dal Molin \\ Paulo José Melaragno Monteiro
}

\section{Resumo}

Ana Paula Kirchheim Norie, Núcleo Orientado para a Inovação da Edificação, Escola de Engenharia Universidade Federal do Rio Grande do Sul

Av. Osvaldo Aranha, 99, $3^{\circ}$ andar Porto Alegre - RS - Brasil CEP 90035-190

Tel: (51) 3308-3518 E-mail: anapaula.k@gmail.com

Rui Barbosa de Souza Programa de Pós-Graduação em Engenharia Civil Universidade de São Paulo Edifício da Engenharia Civil -

Sala 25, Av. Prof. Almeida

Prado, trav. 2, n.83. Cidade Universitária São Paulo - SP -Brasil CEP 05508-900

Tel.: (11) 3091-977 E-mail: rui.souza@poli.usp.br

Denise Carpena Coitinho Dal Molin

Norie, Núcleo Orientado para a Inovação da Edificação, Escola de Engenharia Universidade Federal do Rio Grande do Sul Tel.: (51) 3308-3321 E-mail: dmolin@ufrgs.br

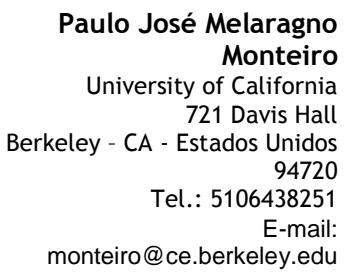

Recebido em 10/12/09

Aceito em 03/03/10

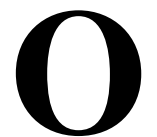

aluminato tricálcico $\left(\mathrm{C}_{3} \mathrm{~A}\right)$ é a fase que reage mais rápido na hidratação do cimento quando em contato com a água. Geralmente, a forma cristalina sintetizada durante o processo de clinquerização é cúbica. No entanto, o íon $\mathrm{Na}^{+}$pode ser incorporado na estrutura cristalina do $\mathrm{C}_{3} \mathrm{~A}$, em substituição ao $\mathrm{Ca}^{2+}$, levando à modificação da forma cristalina cúbica, para a ortorrômbica $\left(\mathrm{Na}-\mathrm{C}_{3} \mathrm{~A}\right)$. Embora alguns estudos tenham investigado a interferência desta fase modificada na hidratação do cimento, algumas lacunas de conhecimento ainda existem. $O$ presente estudo utiliza fases puras sintetizadas em laboratório, para, desta forma, examinar as reações isoladamente. A hidratação destes aluminatos na presença de gipsita foi estudada utilizando calorimetria isotérmica, microscopia eletrônica de varredura (MEV), difração de raios X (DRX) e ensaio de reologia de modo dinâmico, para comprovar e observar o comportamento diferenciado de cada aluminato. Os resultados mostraram que existem grandes diferenças na hidratação de cada aluminato, sendo o $\mathrm{C}_{3} \mathrm{~A}$ ortorrômbico mais reativo nas primeiras idades quando em presença de gipsita, consumindo-a totalmente em poucos minutos. As pastas com $\mathrm{C}_{3} \mathrm{~A}$ ortorrômbico na presença de gipsita apresentaram um calor total liberado no mínimo 10 vezes maior quando comparado às pastas com $\mathrm{C}_{3} \mathrm{~A}$ cúbico. As imagens de MEV e os difratogramas demonstraram que as pastas contendo $\mathrm{C}_{3} \mathrm{~A}$ ortorrômbico reagiram mais rápidas formando cristais maiores de etringita.

Palavras-chave: Aluminato tricálcico cúbico e ortorrômbico. Etringita. Hidratação.

\section{Abstract}

Tricalcium aluminate $\left(C_{3} A\right)$ is the phase that reacts more quickly in the cement hydration when in contact with water. Generally, the crystalline form of $C_{3} A$ synthesized during clinkerization is cubic. However, $\mathrm{Na}^{+}$can be incorporated into the crystalline lattice of $C_{3} A$, replacing the $\mathrm{Ca}^{2+}$, leading to the formation of orthorhombic $\mathrm{C}_{3} \mathrm{~A}\left(\mathrm{Na}-\mathrm{C}_{3} \mathrm{~A}\right)$. Although some studies have investigated the influence of this polymorphous on cement hydration, some knowledge gaps still exist. This study uses pure phases synthesized in laboratory to analyze the reactions independently, isolating the reactions from the others phases. Hydration reactions of $C_{3} A$ in presence of gypsum were investigated by isothermal calorimetry, scanning electron microscopy (SEM), X-ray diffraction (XRD), and dynamic mode rheology. The results showed differences in the hydration of each aluminate, indicating that the orthorhombic phase is more reactive at early ages in the presence of gypsum, consuming them very quickly. The pastes mixed with orthorhombic $C_{3} A$ and gypsum presented a total heat released at least 10 times greater than the ones made with cubic $C_{3} A$. The SEM images and the XRD patterns demonstrate that the pastes containing orthorhombic $C_{3} A$ reacted at a faster rate, and the ettringite crystals formed were also longer.

Keywords. Cubic and orthorhombic tricalcium aluminate. Ettringite. Hydration. 


\section{Introdução}

Calor de hidratação pode ser definido como a quantidade de calor que é desprendida durante as reações de hidratação das fases do cimento. Por ser baixa a condutividade térmica do concreto, em obras que utilizam grandes volumes de concreto, a elevada liberação de calor devido à reação de hidratação pode gerar fissuras por retração térmica. Como uma regra geral, Ramachandran e Beaudoin (1999) destacam que o índice de hidratação das fases no cimento se processa na seguinte ordem: $\mathrm{C}_{3} \mathrm{~A}>\mathrm{C}_{3} \mathrm{~S}>\mathrm{C}_{4} \mathrm{AF}>\mathrm{C}_{2} \mathrm{~S}$. Esse índice depende do tamanho do cristal, de suas imperfeições, de sua distribuição no clínquer, do tamanho das partículas, da área específica, da presença de adições, da temperatura de queima do clínquer, entre outros. Das fases do cimento que mais interferem na quantidade de calor liberado estão o $\mathrm{C}_{3} \mathrm{~S}$ e o $\mathrm{C}_{3} \mathrm{~A}$, por serem as que liberam maior calor de hidratação quando analisadas individualmente. Se, por um lado, classicamente se utilizam de forma preventiva cimentos com baixo calor de hidratação para evitar fissuras de origem térmica, em alguns casos essa medida não é possível, devido às definições prescritas no projeto arquitetônico. O cimento Portland branco, por exemplo, geralmente é utilizado em concretos cromáticos, em que esse material é fundamental para que se atinjam os padrões de qualidade delimitados. A grande diferença na composição química dos cimentos Portland branco e cinza está na limitação do $\mathrm{C}_{4} \mathrm{AF}$, com possibilidade de aumento do teor de $\mathrm{C}_{3} \mathrm{~A}$.

Das fases do clínquer, o aluminato tricálcico $\left(\mathrm{C}_{3} \mathrm{~A}\right)$ é a mais reativa, reagindo instantaneamente com a água, desprendendo rapidamente grande quantidade de calor (300 cal/g, para a fase pura). Para controlar essa reação, mistura-se sulfato de cálcio ao clínquer na moagem. As características de pega (perda de consistência) e enrijecimento (solidificação) de uma pasta de cimento Portland são amplamente determinadas por reações de hidratação envolvendo os aluminatos (MEHTA; MONTEIRO, 2006). A gipsita, ou outra forma de sulfato de cálcio, reage com o $\mathrm{C}_{3} \mathrm{~A}$, formando uma fase intermediária insolúvel, a etringita, o que retarda sua hidratação (NEVILLE, 1997). A quantidade de $\mathrm{C}_{3} \mathrm{~A}$ presente na maioria dos cimentos é relativamente pequena, de $6 \%$ a $10 \%$, excetuando-se o cimento Portland branco, que pode conter teores acima de 10\% (NEVILLE, 1997). Devido a esses elevados teores de $C_{3} A$ em sua composição, a pasta de cimento branco normalmente apresenta tempo de início de pega mais curto quando comparado com o do cimento Portland comum (HAMAD, 1995).
Unindo o fato de que o cimento branco possui teores superiores de $\mathrm{C}_{3} \mathrm{~A}$, podendo chegar a $14 \%$ (KIRCHHEIM, 2003) e de que é constituído por partículas mais finas, podendo ser comparado à finura de um cimento Portland de alta resistência inicial (ARI), se confrontado com outros tipos de cimento, é esperado que concretos produzidos com cimento branco apresentem tempos mais curtos de início de pega, além de uma elevada liberação calor durante a hidratação desse cimento (KIRCHHEIM et al., 2005). Dessa forma, concretagens de elementos estruturais de grandes dimensões, em concreto branco, necessitam ser bem controladas, pois tendem a desenvolver picos de temperatura maiores, em virtude do elevado calor de hidratação nas primeiras idades.

Um exemplo descrito por Selna e Monteiro (2001) foi a pesquisa realizada durante a execução da Catedral Arquidiocesana no centro de Los Angeles, nos Estados Unidos, para adequar os materiais utilizados e dosar um concreto cromático executado para a estrutura e as paredes dessa obra. $\mathrm{O}$ maior desafio apontado pelos autores foi $\mathrm{o}$ elevado calor liberado pelo concreto de cimento Portland branco pigmentado, com consequente formação de inúmeras fissuras (Figura 1b). Isso pode ser relacionado à maior reatividade do cimento branco e ao fato de a espessura das paredes de concreto armado dessa obra variar de $0,3 \mathrm{~m}$ a $1,5 \mathrm{~m}$, sendo as paredes com maior espessura as mais prejudicadas, visto que a quantidade de massa de concreto era maior.

Outro episódio recente, que ocorreu durante a execução do Museu Iberê Camargo, em Porto Alegre, foi que o concreto, moldado com cimento Portland branco com um teor de $\mathrm{C}_{3} \mathrm{~A}$ acima de $9 \%$, apresentava a pega em tempo inferior ao necessário para a concretagem das paredes, vigas e pilares. Por exemplo, em um proporcionamento de concreto, testado nos protótipos durante a fase inicial de desenvolvimento da mistura, sendo utilizados $380 \mathrm{~kg}$ de cimento por metro cúbico de concreto, em dias de temperatura acima de $25{ }^{\circ} \mathrm{C}$, o concreto que inicialmente possuía o abatimento de aproximadamente $22 \mathrm{~cm}$, após $15 \mathrm{~min}$, reduziase a $12 \mathrm{~cm}$ e, após meia hora, a $6 \mathrm{~cm}$, o que impossibilitava o transporte desse material da central de produção até o canteiro de obra (Figura 2a). Além disso, devido ao curto tempo de pega, não era obtido um bom adensamento do concreto, formando camadas nas paredes em virtude da rápida perda de trabalhabilidade (Figura $2 \mathrm{~b}$ - vide setas). 


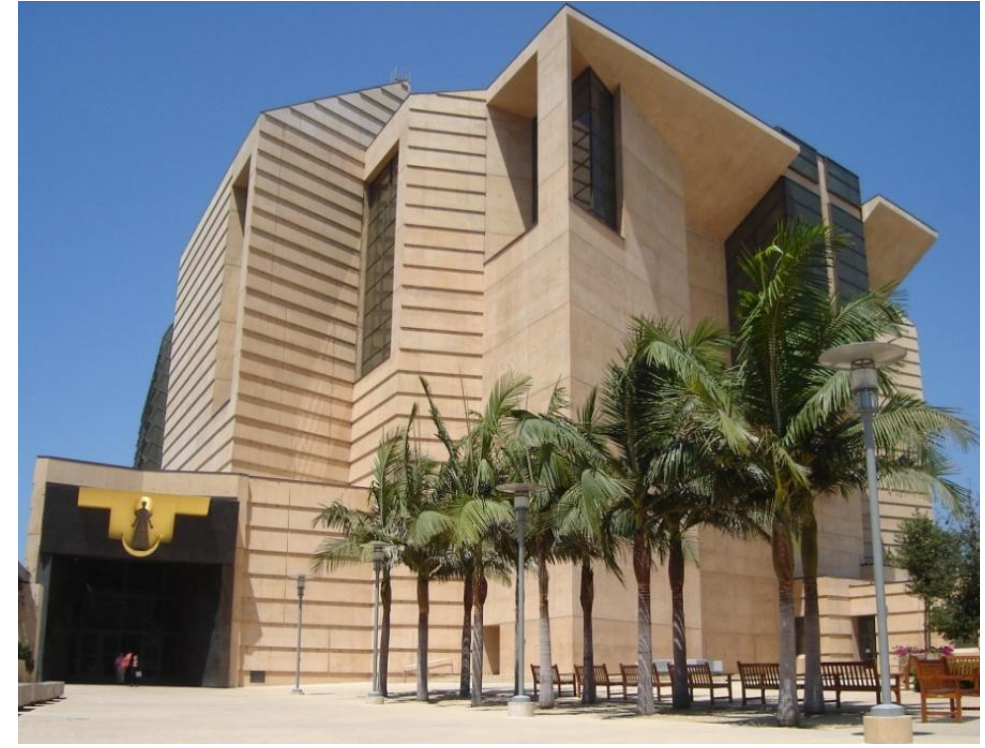

(a) Vista geral da obra

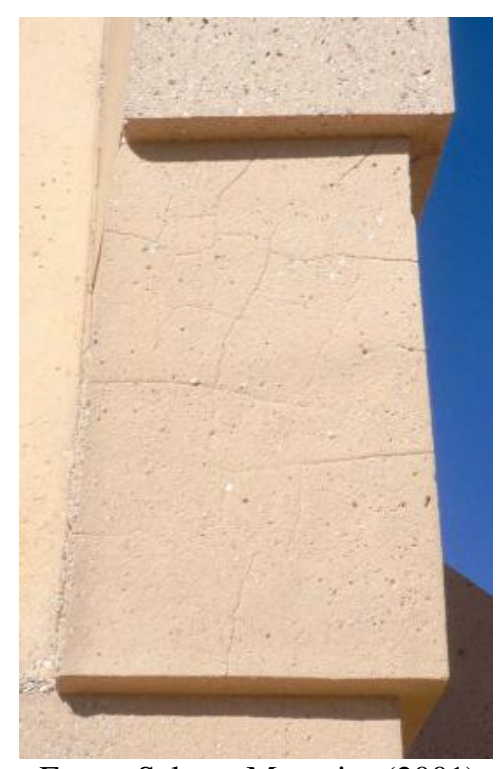

Fonte: Selna e Monteiro (2001)

(b) Fissuras de origem térmica

Figura 1 - Catedral Arquidiocesana de Los Angeles, EUA

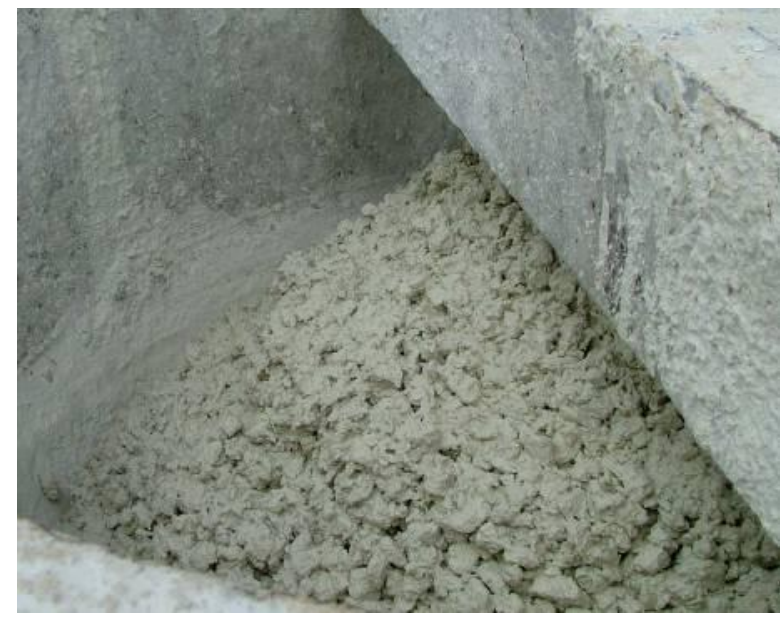

(a) Concreto com baixa trabalhabilidade em poucos minutos após a mistura

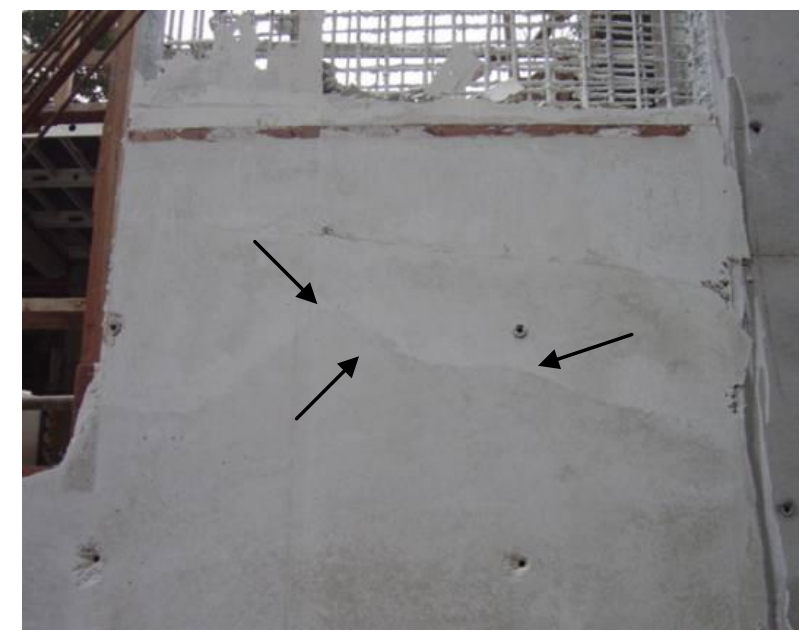

(b) Camadas observadas devido aos problemas de adensamento em função da perda de trabalhabilidade do concreto

Figura 2 - Imagens de um dos protótipos do Museu Iberê Camargo, em Porto Alegre

Para que fossem evitados esses problemas, os pesquisadores analisaram pontos relacionados à perda de eficiência do aditivo dispersante e à presença do filler calcário no cimento Portland branco. Uma das hipóteses para explicar o ocorrido foi o elevado teor de $\mathrm{C}_{3} \mathrm{~A}$ encontrado no cimento branco. No entanto, comparativamente, cimentos Portland comuns com esses teores de $\mathrm{C}_{3} \mathrm{~A}$ não apresentam tal comportamento.

Ao analisar fatores relacionados à hidratação do $\mathrm{C}_{3} \mathrm{~A}$, observa-se que duas formas cristalinas podem ser encontradas em clínqueres industriais: a cúbica e a ortorrômbica (TAYLOR, 1990). A forma ortorrômbica se diferencia da cúbica pela incorporação de íons alcalinos $\left(\mathrm{Na}^{+}\right.$ou $\left.\mathrm{K}^{+}\right)$na estrutura cristalina do $\mathrm{C}_{3} \mathrm{~A}$ em substituição ao $\mathrm{Ca}^{2+}$ (REGOURD; GUINER, 1975). Gobbo et al. (2004), a partir de estudo de oito cimentos Portland brancos e comuns, destacam que os álcalis encontrados nesses cimentos são $\mathrm{Na}_{2} \mathrm{O}$, para o clínquer branco, e $\mathrm{K}_{2} \mathrm{O}$ para o clínquer de cimento comum, o que pode explicar as diferenças entre os dois tipos de cimentos ante a influência do $\mathrm{C}_{3} \mathrm{~A}$ no início da pega. Além disso, há pesquisadores (GLASSER; MARINHO, 1984; WACHTLER et al., $1986^{1}$ apud MASSAZZA; DAIMON, 1992; PAURI; COLLEPARDI, 1987;

\footnotetext{
${ }^{1}$ WACHTLER, H.-J. et al. Uber den Einfluss BrennstoffbeDingter Akzessorien auf die Hydratation des Trikalziumaluminats. Silikattechnick, v. 4, p. 127-131, 1986.
} 
STEPHAN; WISTUBA, 2006) que defendem que a forma ortorrômbica é mais reativa que a cúbica em misturas com sulfatos de cálcio presentes. Por outro lado, outros pesquisadores (BOIKOVA; DOMANSKY, 1977; REGOURD et al., 1980; ODLER; WONNEMANN, 1983; TAYLOR, 1990; SAMET; SARKAR, 1997) acreditam no contrário. Percebe-se a falta de consenso entre os pesquisadores, sendo esta uma das lacunas que será abordada neste artigo.

Segundo Quarcioni (2008), uma forma eficiente e simplificada de monitorar a velocidade de hidratação é mediante o acompanhamento dessas reações por meio de curvas da evolução do calor, geralmente utilizadas em estudos das fases puras do clínquer. Mesmo que essas curvas não respondam a questões sobre o mecanismo, são úteis para a correlação de dados experimentais conhecidos com parâmetros individuais envolvendo a evolução de calor.

Para o bom entendimento do que está ocorrendo durante a hidratação de materiais cimentícios, o tipo de técnica disponível irá influenciar diretamente nos resultados. Dessa forma, quanto mais preciso o microscópio e mais sensível o difratômetro, o calorímetro ou qualquer equipamento utilizado, melhor será a saída de dados e, com isso, a análise dos resultados se tornará mais confiável ao pesquisador responsável. A necessidade da utilização de diversas técnicas é devida aos vários produtos de hidratação formados e à rapidez de sua formação. Um leque de técnicas, desde clássicas análises até a utilização de modernos equipamentos que utilizam a radiação síncrotron, vem sendo utilizado para esse fim.

Durante a execução deste trabalho buscou-se utilizar e, algumas vezes, adequar técnicas que permitissem o estudo da hidratação in situ, bem como se fez uso de técnicas tradicionais complementares, todas elas fundamentais para traçar contribuições na análise da hidratação do aluminato tricálcico cúbico e ortorrômbico.

Dessa forma, mostra-se interessante a caracterização do comportamento das fases do cimento, principalmente quando se trata dos teores de aluminatos (cúbico e ortorrômbico), visto que esse seria um passo a mais na prevenção de problemas futuros relacionados ao tempo de início de pega, trabalhabilidade e fissuras térmicas. Este trabalho tem por objetivo apontar alguns resultados observados em um amplo estudo sobre a interferência da forma cristalina do aluminato tricálcico na evolução de calor, formação de etringita e reologia em tempo real de pastas desses materiais na presença de gipsita. Mais informações podem ser encontradas em Kirchheim (2008).

\section{Materiais e métodos de investigação}

\begin{abstract}
Materiais
$\mathrm{O}$ presente estudo utiliza fases do clínquer sintetizadas em laboratório $\left(\mathrm{C}_{3} \mathrm{~A}\right.$ cúbico $\left[\mathrm{C}_{3} \mathrm{~A}\right.$ puro] e ortorrômbico $\left.\left[\mathrm{Na}-\mathrm{C}_{3} \mathrm{~A}\right]\right)$. Acredita-se que, observando a cinética da reação dessas fases puras, isoladas das demais, pode-se apontar as diferenças entre suas reatividades e suas características na hidratação do cimento. As amostras de aluminato tricálcico $\left(\mathrm{C}_{3} \mathrm{~A}\right)$, na forma cristalina cúbica e ortorrômbica, foram obtidas no Laboratório de Tecnologia da Construção (Construction Technology Laboratories - CTL), na cidade de Skokie, estado de Ilinois, nos Estados Unidos. A gipsita $\left(\mathrm{CaSO}_{4} \cdot 2 \mathrm{H}_{2} \mathrm{O}\right)$ foi obtida na Fisher Scientist, Pittsburgh, Filadélfia, Estados Unidos.
\end{abstract}

Para confirmar a pureza e composição das fases foram realizadas analises por difração de raios $\mathrm{X}$ em um equipamento PANalytical XPert Pro. Os resultados foram analisados mediante a comparação de fichas (ICDD PDF No.38-1429 para a amostra cúbica e ICDD PDF No.26-0958 para a amostra ortorrômbica), como proposto por Regourd et al. (1973).

A granulometria a laser da distribuição das partículas foi feita no Laboratório de Cerâmica (LACER), da Universidade Federal do Rio Grande do Sul, com o uso do aparelho CILAS 1180, em meio líquido, à base de álcool isopropílico, e é apresentada na Tabela 1.

\section{Métodos}

\section{Calorimetria}

Para o estudo da hidratação dos aluminatos foi empregado um calorímetro de condução TamAIR, da marca TA Instruments, com acessório integrado STIRRER (misturador elétrico), que permitiu a mistura das pastas em seu interior. Esse estudo foi realizado no Laboratório de Microestrutura da Escola Politécnica da Universidade de São Paulo (Epusp).

$\mathrm{O}$ procedimento adotado consistiu na pesagem do material seco de 3 g a 6 g $\left(\mathrm{C}_{3} \mathrm{~A}\right.$ cúbico ou ortorrômbico mais gipsita). A quantidade de água foi pesada com o auxílio de uma seringa. Os materiais secos foram colocados no porta-amostra do calorímetro e deixados em repouso por $45 \mathrm{~min}$, para estabilização do sinal do equipamento. Em seguida, foi acionada a aquisição de dados e adicionada a água, o que durou $1 \mathrm{~min}$. Após a adição de água, ligou-se o misturador elétrico, que 
homogeneizou a pasta no interior do calorímetro por $2 \mathrm{~min}$. A temperatura do sistema foi mantida constante em $25{ }^{\circ} \mathrm{C}$ durante todo o período de aquisição dos dados (24 h).

A proporção em massa de materiais das pastas pode ser visualizada na Tabela 2 .

Esse calorímetro possui dois sensores, um na ampola de vidro que contém a amostra, e outro em uma ampola de vidro idêntica, mas vazia. Os sinais coletados pelos sensores possuem uma correlação com a quantidade de calor liberada pela amostra, que é uma constante interna do equipamento. Essa quantidade de calor pode ser representada em calorias, por exemplo (unidade de calor); dessa forma, o próprio equipamento converte a quantidade de calor para $\mathrm{J}$ (exemplo, $1 \mathrm{cal}=4,186$ J). A resposta do equipamento é resultado da subtração do calor liberado pela ampola com amostra pelo calor acumulado pela ampola vazia.

As respostas do equipamento podem ser lidas como a quantidade de calor em $\mathrm{J}$ para cada tempo de aquisição de dado, gerando um gráfico de calor (em joule) versus tempo (em horas); ou a derivada dessa curva, que é uma curva resultante de fluxo de calor (em watts) versus tempo (em horas).

Até então nenhum parâmetro externo é necessário para a realização desses gráficos, pois é uma resposta pronta do equipamento. No entanto, para a apresentação dos resultados, esse valor foi dividido pela massa de $\mathrm{C}_{3} \mathrm{~A}$ de cada amostra, resultando em gráficos de $\mathrm{kJ} / \mathrm{kg}$.

\section{Microscopia Eletrônica de Varredura e Difração de Raios $\mathrm{X}$}

Para análise de microscopia eletrônica de varredura, as amostras foram misturadas manualmente, por $2 \mathrm{~min}$, em um recipiente. Em seguida, foram acomodadas no porta-amostra, onde permaneceram curando em uma câmara úmida $(\mathrm{UR}=100 \%)$, cobertas por um filme plástico, por 7 dias.

Amostras selecionadas dessas pastas foram secas no próprio equipamento utilizado para revestir a amostra, em um sistema a vácuo. Então, as amostras foram revestidas com uma capa de ouro e investigadas por microscopia eletrônica de varredura (MEV), usando um microscópio de alta resolução, da marca Hitachi S-5000. O microscópio trabalha em cold field emission $\mathrm{MEV}$, opera entre $0,5 \mathrm{kV}$ e $30 \mathrm{kV}$ e possui uma magnificação de $30 x$ até $800.000 x$. A resolução das imagens de $0,6 \mathrm{~nm}$ (com $30 \mathrm{kV}$ ) e de $3,5 \mathrm{~nm}$ (com $1 \mathrm{kV}$ ) são possíveis com imagens por elétrons secundários. Os ensaios foram realizados no Electron Microscope Laboratory na University of California, Berkeley.

Para esse ensaio, a proporção de materiais utilizado foi de 1:1,9 $-\mathrm{C}_{3} \mathrm{~A}$ :gipsita, mesma relação utilizada na técnica de calorimetria apresentada anteriormente, com a diferença de que se manteve a relação da quantidade de água identificada pelo cálculo estequiométrico, baseado em Mehta (1973), o que levou a uma relação água/materiais $\operatorname{secos}$ de 0,6. As quantidades de materiais utilizados podem ser vistas na Tabela 3 .

\begin{tabular}{l|c|c}
\hline & $\mathbf{C}_{\mathbf{3}} \mathbf{A}$ cúbico $(\boldsymbol{\mu m})$ & $\mathbf{C}_{\mathbf{3}} \mathbf{A}$ ortorrômbico $(\boldsymbol{\mu m})$ \\
\hline $\mathbf{1 0 \%}$ diâmetro & 5,74 & 1,64 \\
\hline $\mathbf{5 0 \%}$ diâmetro & 24,31 & 16,04 \\
\hline $\mathbf{9 0 \%}$ diâmetro & 45,00 & 36,34 \\
\hline Diâmetro médio & 25,16 & 18,43 \\
\hline
\end{tabular}

Tabela 1 - Resultados da análise de granulometria a laser

\begin{tabular}{c|c|c|c|c|c|c}
\hline $\begin{array}{c}\text { Proporção de mistura } \\
\left(\mathbf{C}_{\mathbf{3}} \mathbf{A} \mathbf{\text { :gip}}\right)\end{array}$ & Tipo $\mathbf{C}_{\mathbf{3}} \mathbf{A}$ & $\mathbf{C}_{\mathbf{3}} \mathbf{A}(\mathbf{g})$ & & Gipsita $(\mathbf{g})$ & Água $(\mathbf{g})$ & $\mathbf{a} / \mathbf{m s}$ \\
\hline \multirow{2}{*}{$1: 1,9$} & \multirow{2}{*}{ cúbico } & 0,5 & - & 0,95 & 1,74 & 1,2 \\
\cline { 3 - 7 } & & 1 & - & 0,6 & 1,92 & 1,2 \\
\hline \multirow{2}{*}{$1: 0,6$} & \multirow{2}{*}{ ortorrômbico } & 0,94 & - & 1,787 & 3,272 & 1,2 \\
\cline { 3 - 6 } & & 1,7 & - & 1,02 & 3,274 & 1,2 \\
\hline
\end{tabular}

Tabela 2 - Proporção de materiais nas pastas para ensaio de calorimetria

\begin{tabular}{c|c|c|c|c|c}
\hline $\begin{array}{c}\text { Proporção de mistura } \\
\left(\mathbf{C}_{\mathbf{3}} \mathbf{A} \text { :gip) }\right.\end{array}$ & Tipo $\mathbf{C}_{\mathbf{3}} \mathbf{A}$ & $\mathbf{C}_{\mathbf{3}} \mathbf{A}(\mathbf{g})$ & Gipsita (g) & Água (g) & $\mathbf{a} / \mathbf{m s}$ \\
\hline $1: 1,9$ & Cúbico ou ortorrômbico & 2,5 & 4,78 & 4,3 & 0,6 \\
\hline
\end{tabular}

Tabela 3 - Proporção de materiais nas pastas para análise em MEV e DRX 
A difração de raios $X$ (DRX) foi feita com uma parte das amostras utilizadas no ensaio anterior (MEV). Com 7 dias de idade, as amostras úmidas foram colocadas em acetona, com o objetivo de retirar a água e parar a hidratação e, em seguida, essa amostra foi seca e mantida em vácuo, realizando-se difração de raios $\mathrm{X}$ na sequência. Os ensaios foram feitos no Laboratório de Cerâmica (LACER), da Universidade Federal do Rio Grande do Sul, com difratômetro modelo Phillips X'Pert MPD, com tubo cerâmico modelo PW3373/00 e detector proporcional modelo PW 3011/10, raios X $\mathrm{CuK} \infty(\lambda=1,5418 \AA)$, com passo de $0,05^{\circ}$, tempo de $1 \mathrm{~s}$ e fendas de $1 / 2^{\circ}$.

\section{Ensaio de reologia de modo dinâmico}

Foram feitos ensaios de reologia nessas pastas com o intuito de verificar as características in situ do endurecimento delas. Reologia é definida como a ciência da deformação e fluidez de materiais, e descreve a inter-relação entre a tensão, a deformação e o tempo (BARNES et al., 1989²; WHORLOW, $1992^{3}$ apud ESPING, 2007). Geralmente é aplicada em materiais mais ou menos fluidos, ou materiais que exibem uma tensão de escoamento dependente do tempo.

Ensaios oscilatórios são indicados quando se pretende avaliar a cinética da hidratação do cimento sem afetar a estrutura que se forma continuamente com o tempo, graças à capacidade de aplicação de deformações pequenas, mantendo a estrutura em repouso (BETIOLI, 2007). Muitos pesquisadores vêm utilizando esse método para verificar a evolução das mudanças estruturais de pastas de cimento (KIRBY; LEWIS, 2002; SUN; VOIGT, 2006), de fases puras como o silicato tricálcico $\left(\mathrm{C}_{3} \mathrm{~S}\right)$ (NACHBAUR et al., 2001), entre outros.

A base de ensaios oscilatórios está na aplicação de uma tensão ou deformação senoidal na amostra. A resposta à deformação ou tensão, respectivamente, também é senoidal mas associada a um ângulo de fase $(\delta)$. O valor desse ângulo será entre $0^{\circ}$ e $90^{\circ}, \mathrm{o}$ que limita o valor de material idealmente elástico ou idealmente viscoso respectivamente.

O procedimento experimental adotado foi baseado em Nachbaur et al. (2000) e Sun e Voigt (2006). Os autores chamam essa técnica de reologia de modo dinâmico.

Neste estudo, a análise das tensões/deformações foi realizada em um reômetro Haake RheoStress
600 - Thermo Electron Corporation (Figuras 3 e 4), na Universitat Politècnica de Cataluña, Departamiento de Inginieria de la Construcción, Barcelona, Espanha.

Um cilindro coaxial com diâmetro de $8 \mathrm{~mm}$ foi utilizado (método de placas paralelas). O espaço entre o cilindro e a base de mesmo tamanho foi definido em $2 \mathrm{~mm}$. A placa inferior era estacionária. $\mathrm{Na}$ base desses cilindros havia ranhuras para evitar o deslizamento da amostra na superfície das placas.

As pastas, com os mesmos proporcionamentos das analisadas em MEV e DRX (Tabela 3), eram misturadas manualmente por 2 min e colocadas na base do cilindro, como mostra a Figura 5. Os excessos laterais eram retirados com uma espátula.

Após a transferência do material ao reômetro, uma taxa de cisalhamento (pre shear) de aproximadamente $600 \mathrm{~s}-1$ foi aplicada por $30 \mathrm{~s}$, com o objetivo de se iniciar a acomodação das partículas dos materiais. Esse procedimento foi adaptado de Sun e Voigt. (2006), que se basearam em Tattersall e Banfill (1983). Então, as pastas foram deixadas em repouso por $1 \mathrm{~min}$, no intuito de que as partículas da pasta entrassem em equilíbrio estrutural. Em seguida, a frequência de 5 $\mathrm{rad} / \mathrm{s}$ (velocidade angular) foi mantida constante até o final das análises (aproximadamente $9 \mathrm{~min}$ após a mistura do material com a água). Vários estudos prévios foram realizados, como, por exemplo, varreduras de frequências, até que os parâmetros utilizados foram definidos.

A temperatura foi controlada em $20 \pm 1{ }^{\circ} \mathrm{C}$, a qual foi mantida com o auxílio de um fluxo contínuo de água em um espaço próximo ao porta-amostra cilíndrico, no reômetro.

\footnotetext{
2 BARNES, H. A.; HUTTON, J. F.; WALTERS, K. An introduction

to rheology. Elsevier: Amsterdam, 1989.

${ }^{3}$ WHORLOW, R. W. Rheological techniques. Ellis Harwood,

Chichester, 1992.
} 


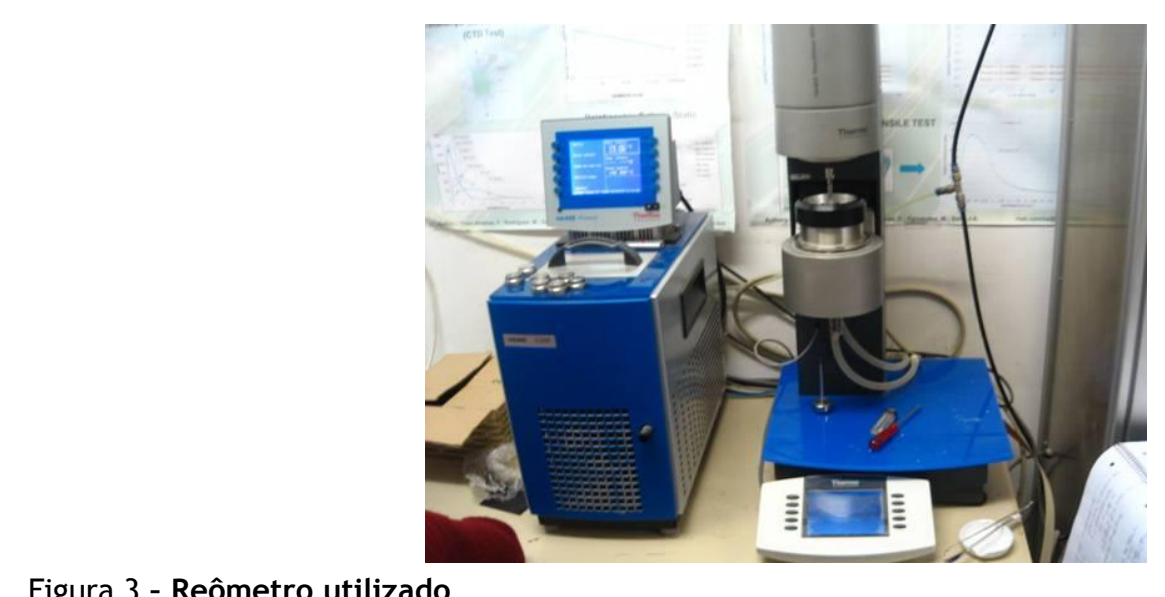

Figura 3 - Reômetro utilizado

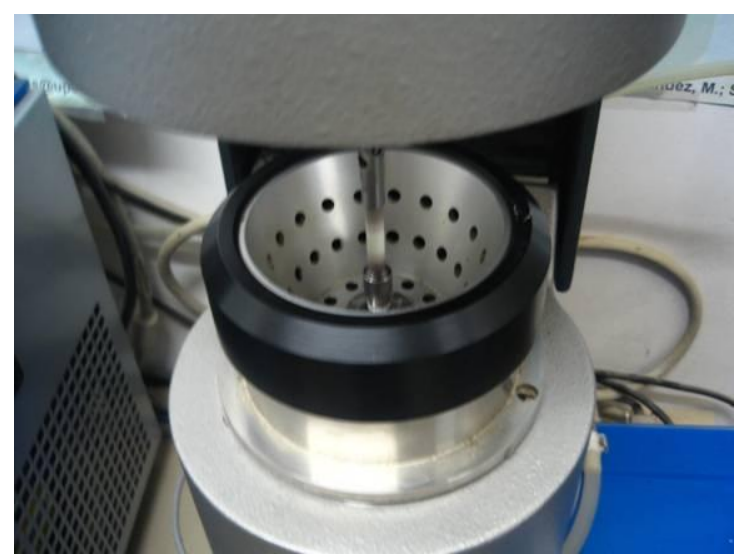

Figura 4 - Detalhe do porta-amostra cilíndrico

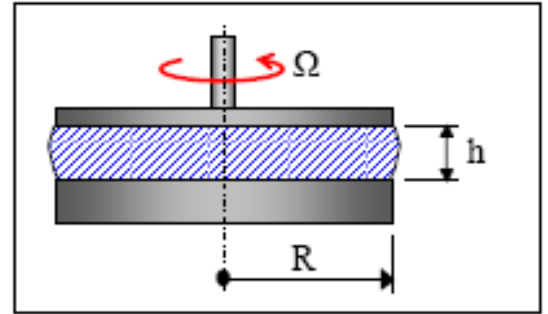

Fonte: Esping (2007)

Figura 5 - Esquema do porta-amostra cilíndrico

\section{Resultados}

\section{Calorimetria}

O gráfico da Figura 6 apresenta as curvas de calor total liberado $(\mathrm{kJ} / \mathrm{kg})$ nas análises das pastas de $\mathrm{C}_{3} \mathrm{~A}$ cúbico e ortorrômbico, na presença de gipsita em duas proporções de mistura.

Analisando os resultados observa-se que o calor total liberado pela amostra de $\mathrm{C}_{3} \mathrm{~A}$ cúbico e gipsita na relação $1: 1,9$ foi maior quando comparada com a relação 1:0,6. As velocidades de reação para as pastas de $\mathrm{C}_{3} \mathrm{~A}$ ortorrômbico e gipsita, nas duas proporções de mistura analisadas, foram bastante diferentes, sendo na pasta com 1:0,6 $\left(\mathrm{C}_{3} \mathrm{~A}_{\mathrm{o}}\right.$ : gip $)$ o calor total liberado cerca de $500 \mathrm{~kJ} / \mathrm{kg}$ inferior ao da pasta com 1:1,9.

Nas pastas com $\mathrm{C}_{3} \mathrm{~A}$ cúbico houve a liberação de menos de $100 \mathrm{~kJ} / \mathrm{kg}$ ao longo das $24 \mathrm{~h}$ de análise, enquanto as pastas com $\mathrm{C}_{3} \mathrm{~A}$ ortorrômbico quase alcançaram $1.100 \mathrm{~kJ} / \mathrm{kg}$ (pasta com 1:1,9) e 400 $\mathrm{kJ} / \mathrm{kg}$ (pasta 1:0,6) ao final de $24 \mathrm{~h}$.

$\mathrm{Na}$ presença de gipsita, no início das reações a velocidade é a mesma. Acredita-se que os cristais que se formam ao redor do $\mathrm{C}_{3} \mathrm{~A}$ cúbico, pela reação desse aluminato com a gipsita, imediatamente paralisaram a reação, indicando que esse $\mathrm{C}_{3} \mathrm{~A}$ é menos solúvel. 
No entanto, tal fato não impede a continuidade da reação do $\mathrm{C}_{3} \mathrm{~A}$ ortorrômbico, percebendo-se a falta de eficiência da gipsita na redução da quantidade de calor liberado na reação com $\mathrm{C}_{3} \mathrm{~A}$ ortorrômbico, funcionando aparentemente como um otimizador das reações.

Segundo as hipóteses apontadas por Glasser e Marinho (1984), a facilidade da liberação do íon $\mathrm{Na}^{+}$da estrutura do $\mathrm{C}_{3} \mathrm{~A}$ ortorrômbico aumenta a dissolução dos aluminatos, elevando também o calor de hidratação, o que pode ser correlacionado à presença maior ou menor de sulfatos na mistura. Corroborando os resultados apresentados, em uma mistura de $\mathrm{C}_{3} \mathrm{~A}$ :gipsita $-1: 0,083$ e relação água/materiais $\operatorname{secos}=0,75$, Stephan e Wistuba (2006) observaram a hidratação de amostras de $\mathrm{C}_{3} \mathrm{~A}$ cúbico e ortorrômbico por calorimetria de condução. Nessas condições, o $\mathrm{C}_{3} \mathrm{~A}$ ortorrômbico, quando comparado ao $\mathrm{C}_{3} \mathrm{~A}$ cúbico, também liberou uma quantidade maior de calor durante as primeiras $3 \mathrm{~h}$ de hidratação. Após esse período a amostra apresentou comportamento similar para os dois aluminatos.

Novos ensaios de calorimetria, termogravimetria e difração de raios $\mathrm{X}$ em tempo real estão sendo realizados em parceria com pesquisadores da USP para comprovar esse comportamento e serão publicados em breve.

\section{Microscopia eletrônica de varredura, difração de raios $X$}

Os resultados obtidos na análise dos produtos formados das pastas de $\mathrm{C}_{3} \mathrm{~A}$ cúbico $\mathrm{e}$ ortorrômbico, na relação $\mathrm{C}_{3} \mathrm{~A}$ :gipsita $=1: 1,9$, com redução no teor de água da mistura $(\mathrm{a} / \mathrm{mat}$. $\mathrm{Sec}=$ $0,6)$, são apresentados a seguir.

A Figura 7 (as setas indicam os limites das fôrmas) apresenta o aspecto das pastas de cada $\mathrm{C}_{3} \mathrm{~A}$, após curadas em câmara úmida por 7 dias. Percebem-se a retração da pasta com o $\mathrm{C}_{3} \mathrm{~A}$ cúbico e a expansão da pasta com o $\mathrm{C}_{3} \mathrm{~A}$ ortorrômbico. A pasta de $\mathrm{C}_{3} \mathrm{~A}$ cúbico ainda estava úmida com 14 dias de hidratação. As mesmas características foram observadas por Black et al. (2006), tendo os autores utilizado material proveniente do mesmo laboratório em que foram adquiridas as amostras para este estudo. A pasta de $\mathrm{C}_{3} \mathrm{~A}$ ortorrômbico apresentava-se totalmente endurecida.

A Figura 8 apresenta as micrografias do MEV por elétrons secundários da pasta de $\mathrm{C}_{3} \mathrm{~A}$ cúbico, gipsita e água, hidratada por 7 dias.

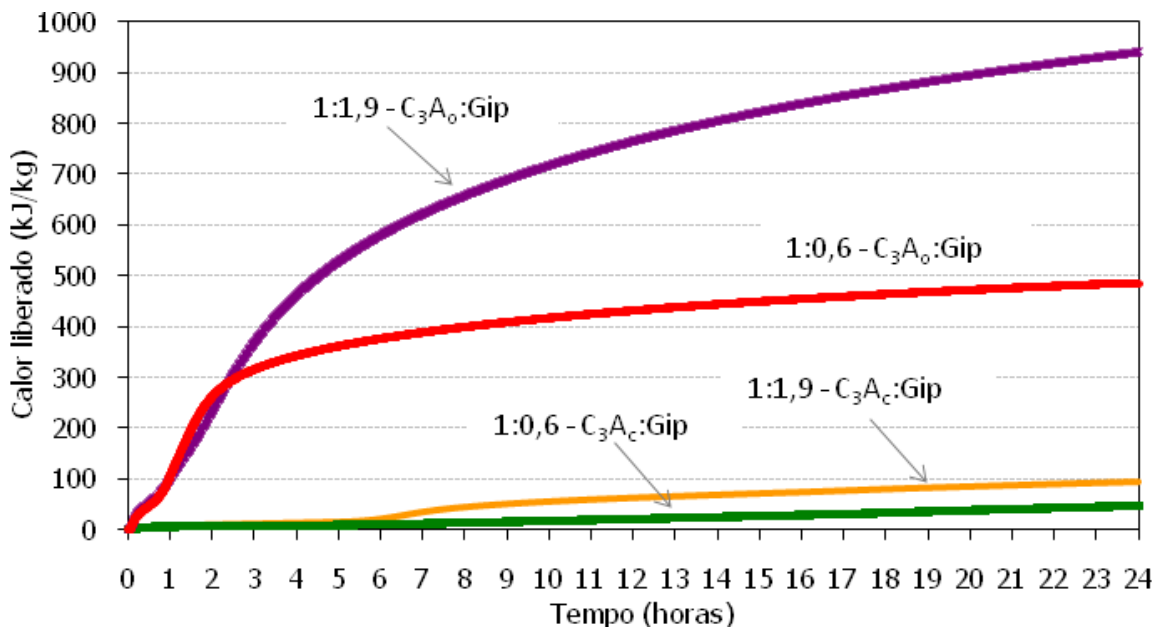

Figura 6 - Curvas da quantidade total de calor liberado durante a hidratação de pastas de $\mathrm{C}_{3} \mathrm{~A}+$ gipsita, em dois proporcionamentos, até $24 \mathrm{~h}$ de hidratação
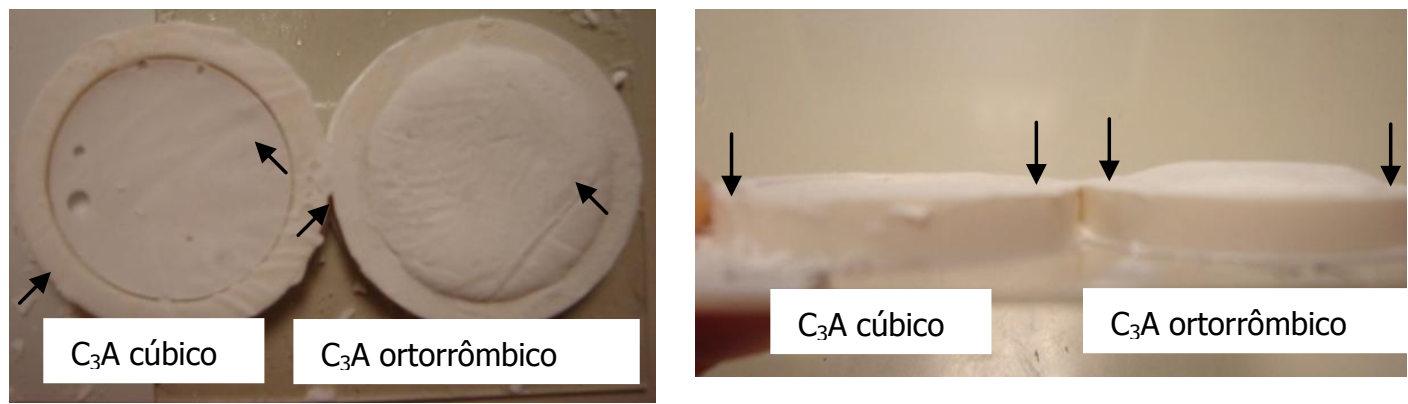

Figura 7 - Aspecto das pastas de $C_{3} A$ (cúbico e ortorrômbico) e gipsita curadas por 7 dias 


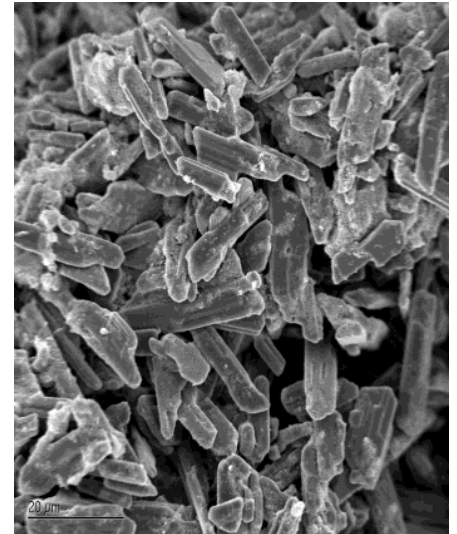

(a) barra de escala $=20 \mu \mathrm{m}$

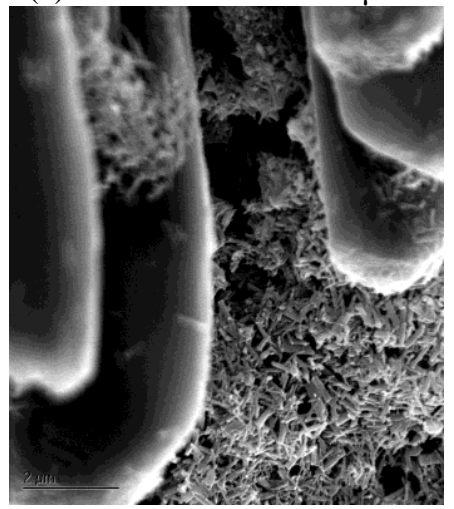

(e) Barra de escala $=2 \mu \mathrm{m}$

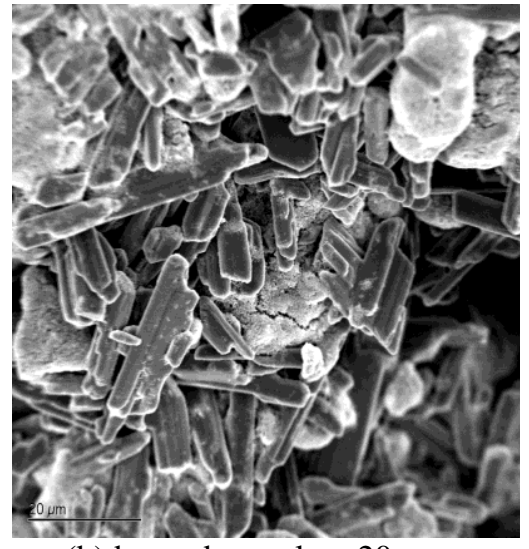

(b) barra de escala $=20 \mu \mathrm{m}$

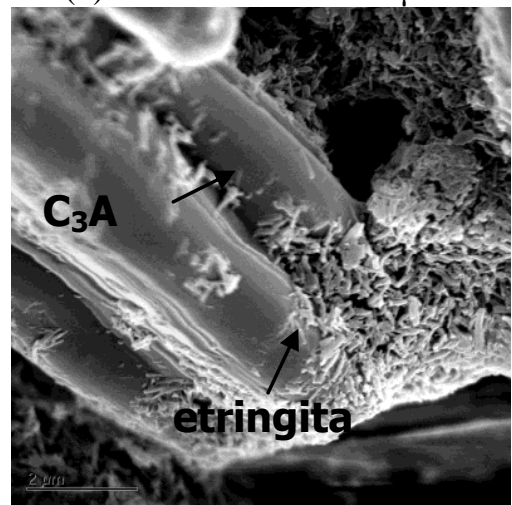

(f) Barra de escala $=2 \mu \mathrm{m}$

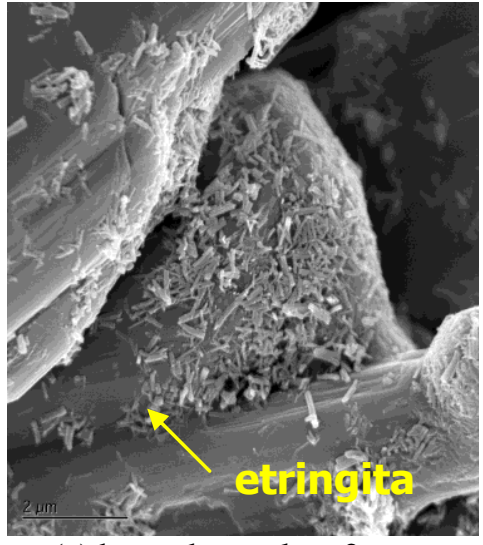

(c) barra de escala $=2 \mu \mathrm{m}$

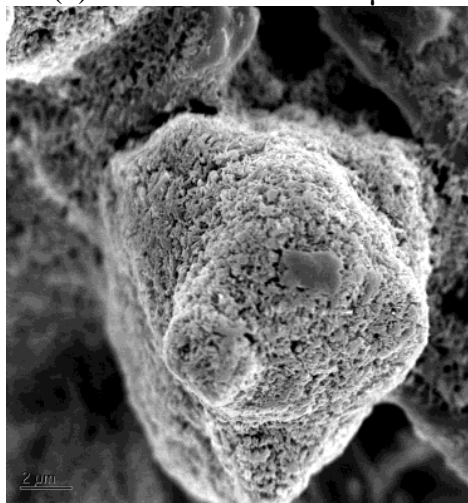

(g) Barra de escala $=2 \mu \mathrm{m}$

Figura 8 - Micrografias da pasta de $C_{3} A$ cúbico + gipsita + água com 7 dias, visualização do $C_{3} A$ cúbico, gipsita e cristais de etringita

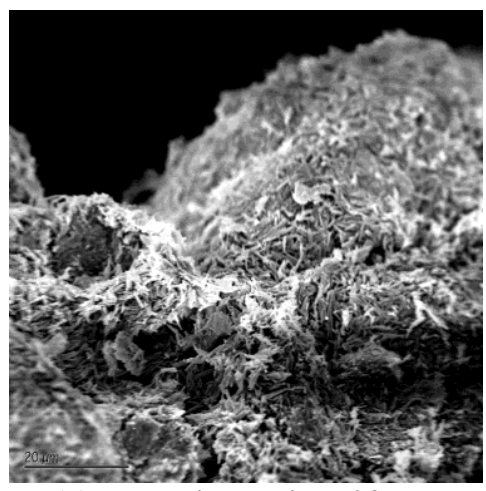

(a) Barra de escala $=20 \mu \mathrm{m}$

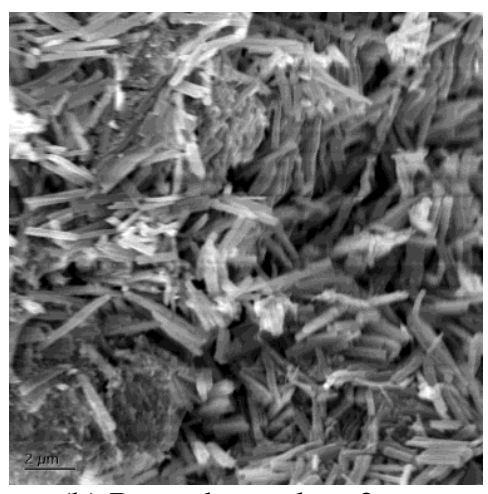

(b) Barra de escala $=2 \mu \mathrm{m}$

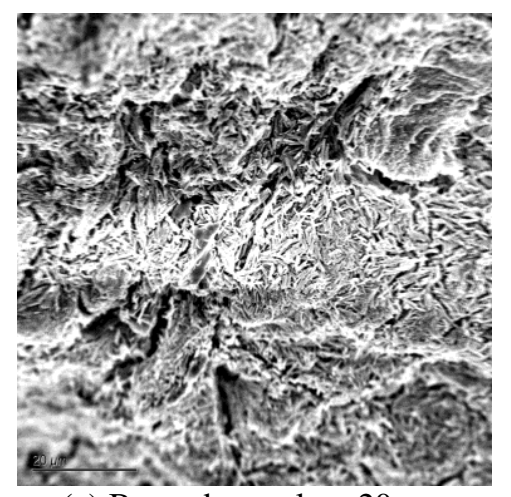

(c) Barra de escala $=20 \mu \mathrm{m}$

Figura 9 - Micrografias da pasta de $C_{3} A$ ortorrômbico + gipsita + água com 7 dias - visualização dos cristais de etringita

Analisando-se essas imagens, pode se dizer que a formação de cristais de etringita é vista próximo aos grãos e envolvendo as partículas de $\mathrm{C}_{3} \mathrm{~A}$. As partículas maiores e tubulares são de gipsita, que ainda não foram consumidas. As agulhas cristalinas de etringita são geralmente menores que $0,5 \mu \mathrm{m}$ em comprimento. As imagens demonstram que aos 7 dias ainda havia gipsita e $\mathrm{C}_{3} \mathrm{~A}$ remanescentes nessa amostra. A confirmação de que as fases vistas nas micrografias são etringita, $\mathrm{C}_{3} \mathrm{~A}$ cúbico e gipsita foi obtida a partir de difração de raios $X$ (Figura 10a).
A Figura 9 apresenta as micrografias da pasta de $\mathrm{C}_{3} \mathrm{~A}$ ortorrômbico, gipsita e água, nas amostras com 7 dias.

As imagens indicam que aos 7 dias a amostra aparentemente não continha gipsita visível, resultados que podem ser comprovados pelos difratogramas da Figura 10b. A formação de etringita pode ser vista pela elevada dissolução da gipsita com consequente precipitação de cristais de etringita. O comprimento dos cristais de etringita é de aproximadamente $1 \mu \mathrm{m}$ a $2 \mu \mathrm{m}$. 


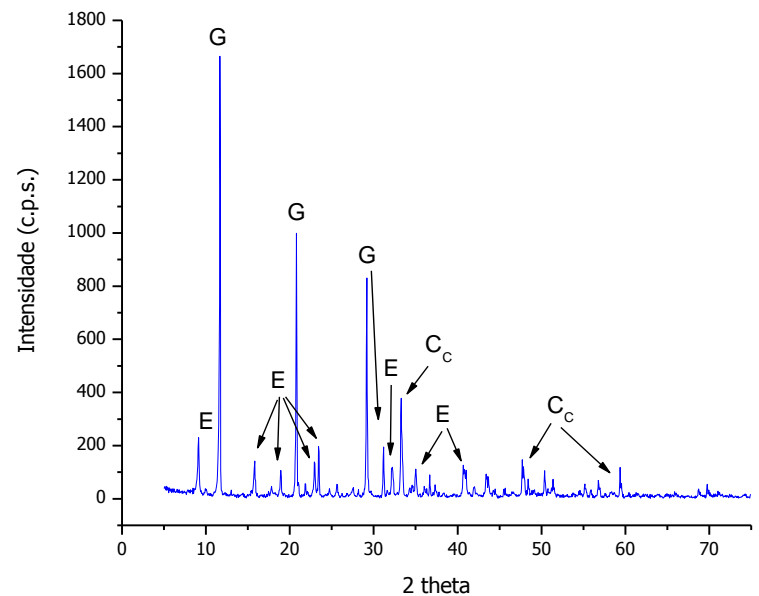

(a) Pasta de $\mathrm{C}_{3} \mathrm{~A}$ cúbico

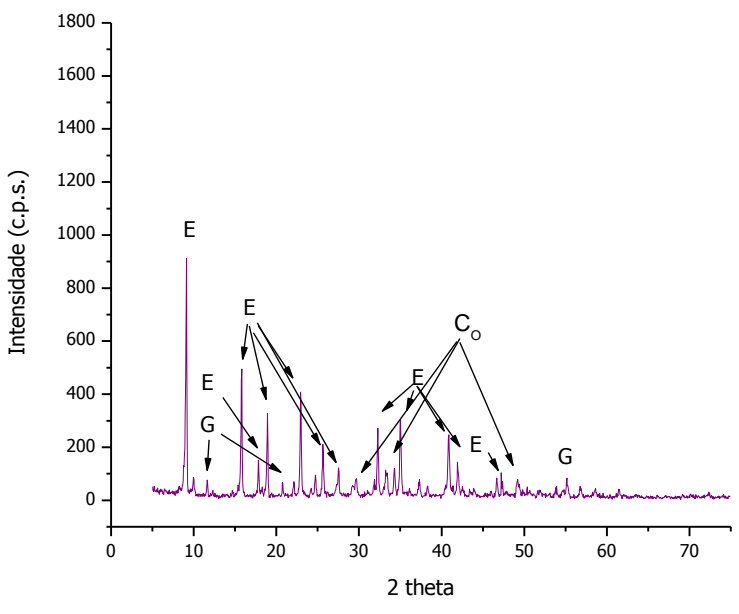

(b) Pasta de $\mathrm{C}_{3} \mathrm{~A}$ ortorrômbico

Legenda:

$$
\begin{aligned}
& \mathrm{E}=\text { etringita; } \\
& \mathrm{G}=\text { gipsita; } \\
& \mathrm{C}_{\mathrm{c}}=\mathrm{C}_{3} \mathrm{~A} \text { cúbico; } \\
& \mathrm{C}_{\mathrm{o}}=\mathrm{C}_{3} \mathrm{~A} \text { ortorrômbico. }
\end{aligned}
$$

Figura 10 - Difratogramas da pasta de $C_{3} A$ cúbico (a)

As imagens, bem como os difratogramas das pastas, permitem concluir que o $\mathrm{C}_{3} \mathrm{~A}$ ortorrômbico, quando comparado ao $\mathrm{C}_{3} \mathrm{~A}$ cúbico nas mesmas condições, reage mais rapidamente, principalmente porque toda a gipsita e o $\mathrm{C}_{3} \mathrm{~A}$ ortorrômbico parecem ter sido consumidos até os 7 dias de hidratação.

Agrega-se também os fatos da formação de cristais maiores (etringita) e da reação total entre o $\mathrm{C}_{3} \mathrm{~A}$ ortorrômbico e a gipsita, o que explica a imagem da Figura 7, onde, visivelmente, observa-se a expansão ocorrida na pasta desses materiais $\left(\mathrm{C}_{3} \mathrm{~A}\right.$ ortorrômbico e a gipsita) durante a hidratação.

\section{Ensaio de Reologia de Modo Dinâmico}

No gráfico da Figura 11 visualiza-se o módulo de armazenamento (G') para cada aluminato, obtidos nos ensaios oscilatórios, cujos resultados são referentes à amostra entre 4 min e 9 min de hidratação.

A média de aumento do G' (rigidez do material sob carregamento dinâmico) para a pasta com o $\mathrm{C}_{3} \mathrm{~A}$ ortorrômbico é de $157,6 \mathrm{~Pa} / \mathrm{s}$, enquanto para a pasta com $\mathrm{C}_{3} \mathrm{~A}$ cúbico é de $96,5 \mathrm{~Pa} / \mathrm{s}$.

O modulo de armazenamento (G') da pasta com $\mathrm{C}_{3} \mathrm{~A}$ ortorrômbico, em função do tempo, aumenta de forma mais rápida que nas pastas com $\mathrm{C}_{3} \mathrm{~A}$ cúbico, o que indica que a pasta com esse $\mathrm{C}_{3} \mathrm{~A}$ endurece mais rapidamente. Um dos parâmetros mais importantes, que governam as propriedades reológicas, entre eles o G', é a fração do volume sólido $(\phi)$ (volume das partículas sólidas/volume de água). Para se ter uma ideia sobre o $\phi$, é necessário saber a densidade das partículas anidras do material sólido. Em princípio, menores $\phi$ implicam maiores G' (endurecimento mais rápido da pasta). O fato de que o índice $G$ ' é maior na amostra ortorrômbica pode indicar que o consumo de água nessa amostra é mais rápido. Entretanto, esse não deve ser o único motivo para essas diferenças no endurecimento, podendo também ser devidas às reações químicas que ocorrem tão rapidamente que o $\phi$ correspondente de cada fase não imponha tanta interferência.

Geralmente considera-se que o alto teor de álcalis acelera a hidratação e o início de pega de materiais cimentícios que o contenham em sua composição (JAWED; SKALNY, $1978^{4}$ apud JUENGER; JENNINGS, 2001), aumentando também a resistência inicial de pastas/argamassas ou concretos moldados com esse material, a qual provavelmente é resultado do aumento da taxa de reação inicial, como pôde também ser comprovado neste estudo de ensaios oscilatórios. No entanto, os autores defendem que os álcalis diminuem a resistência de materiais cimentícios à base destes aos 28 dias ou mais (GEBHARDT, 1995\% BURROWS, $1999^{6}$ apud JUENGER; JENNINGS, 2001). Esses fatores são interessantes de ser analisados futuramente.

\footnotetext{
${ }^{4}$ JAWED, I.; SKALNY, J. Alkalis in Cement: a review. Cement and Concrete Research, v. 8, n. 1, p. 37-51, 1978.

${ }^{5}$ GEBHARDT, R. Survey of North American Portland Cements. Cement and Concrete Aggregates, v. 17, n. 2, p. 145-189, 1995.

${ }^{6}$ BURROWS, R. The Visible and Invisible Cracking of Concrete, ACI monograph No. 11, American Concrete Institute, Farmington Hills, Mich, 1999.
} 


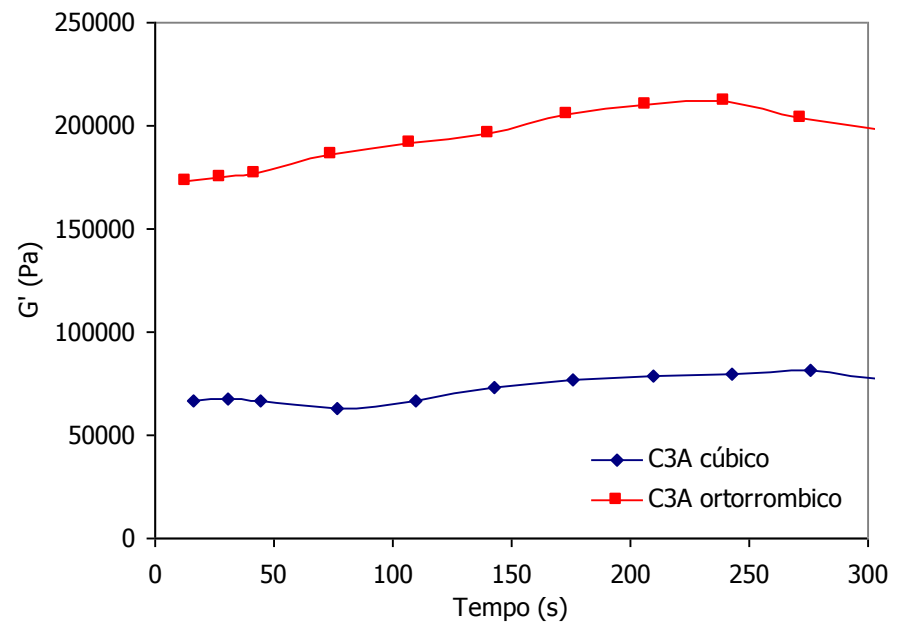

Figura 11 - Módulo de armazenamento (G') de pastas de $C_{3} A$ cúbico e ortorrômbico, gipsita e água

A finura da amostra também interfere nos fenômenos físicos, devendo ser considerada na análise dos resultados. Como visto na análise granulométrica apresentada na Tabela 1 , as partículas do $\mathrm{C}_{3} \mathrm{~A}$ ortorrômbico possuem um diâmetro médio 26,7\% menor que as do cúbico. Isso pode ter afetado a aglomeração das partículas e também aumentado a força iônica entre elas. Novos ensaios deverão ser realizados para comprovar esse comportamento.

\section{Discussões}

Observa-se, a partir dessas análises, que na hidratação do $\mathrm{C}_{3} \mathrm{~A}$ ortorrômbico na presença de gipsita é mais rápida a formação de etringita, quando comparado à do $\mathrm{C}_{3} \mathrm{~A}$ cúbico nas mesmas condições. $\mathrm{O}_{3} \mathrm{~A}$ cúbico é mais sensível quanto ao retardo que a gipsita proporciona durante a hidratação. A gipsita aparentemente imobiliza a dissolução dos aluminatos para a reação.

Glasser e Marinho (1984) propuseram que os estágios iniciais da hidratação são fortemente influenciados pela presença do íon $\mathrm{Na}^{+}$, na molécula do $\mathrm{C}_{3} \mathrm{~A}$ ortorrômbico. Os autores atribuem a isso o fato de que o íon $\mathrm{Na}^{+}$parece ser liberado mais rapidamente a partir da fase ortorrômbica, sugerindo um início de hidratação diferenciado da fase cúbica ou com baixo teor de $\mathrm{Na}^{+}$na estrutura do $\mathrm{C}_{3} \mathrm{~A}$. Pode-se concluir que o $\mathrm{Na}^{+}$, por ser um íon modificador de cadeia, aumenta a dissolução dos aluminatos, facilitando a reação.

De fato, alguns pesquisadores (JAWED; SKALNY, 1978; ${ }^{7}$ SPRUNG; RECHENBER,

\footnotetext{
7 JAWED, I.; SKALNY, J. Alkalis in Cement: a review. Cement
} and Concrete Research, v. 8, n. 1, p. 37-51, 1978.
$1977^{8}$; apud JUENGER; JENNINGS, 2001; LOCHER, 2006) relatam que os álcalis promovem a rápida dissolução do $\mathrm{C}_{3} \mathrm{~A}$, o que acelera a hidratação e o início de pega, e também que o elevado teor de álcalis aumenta o $\mathrm{pH}$ das pastas, o qual, por efeito de íon comum, reduz a concentração de cálcio da solução (JUENGER; JENNING, 2001). Além disso, o alto $\mathrm{pH}$ da solução pode ter facilitado a dissolução de íons anfóteros, como o alumínio.

Essas considerações sobre as diferenças na hidratação do $\mathrm{C}_{3} \mathrm{~A}$ ortorrômbico em presença de gipsita, quando analisadas sob o ponto de vista prático, destacam a importância da continuação de pesquisas para esclarecer o real comportamento do $\mathrm{C}_{3} \mathrm{~A}$ ortorrômbico agindo sinergicamente com as demais fases do clínquer. Além disso, demonstra a importância de análises quanto ao teor ótimo de sulfatos, ou outro material, que se comporte de forma a garantir a trabalhabilidade e a redução do calor liberado durante a hidratação do cimento que contenha essa fase (ortorrômbica) - devido à incorporação dos álcalis na estrutura cristalina do $\mathrm{C}_{3} \mathrm{~A}$ - para que se evitem fissuras de origem térmica no concreto moldado e perdas excessivas de trabalhabilidade.

\section{Conclusões}

Diferentemente do que ocorre em cimentos, em que todas as fases reagem sinergicamente, em sistemas simplificados $\left(\mathrm{C}_{3} \mathrm{~A}\right.$, gipsita e água), as reações são mais claras de se analisar. Porém, não se pode descartar a necessidade de, com o andamento da pesquisa em sistemas mais simples, serem aplicados os conhecimentos adquiridos em ${ }^{8}$ SPRUNG, S.; RECHENBERG, W. Proceedings, Symposium on the
Effect of Alkalies on Properties of Concrete. Cement and Concrete Association, London, 1977, 109 p. 
pastas de cimento, para, assim, observar o comportamento real dessas fases agindo sinergicamente com as demais presentes no cimento

Neste estudo percebeu-se que o $\mathrm{C}_{3} \mathrm{~A}$ cúbico se mostrou muito mais sensível em face da adição de gipsita à mistura, agindo como esperado e relatado em conhecimento científico de outros pesquisadores. A gipsita é bastante efetiva no retardo das reações do $\mathrm{C}_{3} \mathrm{~A}$ cúbico, seja pela formação de uma camada-barreira, seja pela saturação de íons sulfato na solução, paralisando, assim, a dissolução do $\mathrm{C}_{3} \mathrm{~A}$.

$\mathrm{O} \quad \mathrm{C}_{3} \mathrm{~A}$ ortorrômbico demonstrou um comportamento diferenciado do cúbico em todas as análises, mostrando-se mais reativo quando comparado em mesmas condições de análise e proporção de mistura.

A partir dos resultados obtidos, pode-se sugerir que cimentos com altos teores de álcalis presentes no clínquer possivelmente ocasionarão problemas de elevado calor de hidratação desprendido pela hidratação da matriz cimentícia, com consequente retração térmica e fissuração, bem como problemas de trabalhabilidade, devido ao início e ao fim de pega mais curto. Percebe-se a necessidade da definição de um teor ótimo de materiais que retardem esse comportamento mais reativo, bem como melhor entendimento de suas características peculiares durante a hidratação.

Destaca-se a importância da caracterização da forma cristalina nos diversos estudos de materiais cimentícios que os tenham em sua composição. Porém, isso geralmente não é a realidade nos trabalhos acadêmicos, os quais apenas relatam o valor potencial mediante cálculos pelo método de Bogue, a partir do teor de óxidos presentes no material.

Recomenda-se a utilização de ferramentas que permitam o refinamento das fases cúbica $\mathrm{e}$ ortorrômbica desse aluminato, como, por exemplo, a quantificação das fases pelo Método de Rietveld. Assim, com base nas porcentagens reais de cada fase, pode-se delinear considerações mais concretas do comportamento, nos mais diversos casos estudados (estudos de durabilidade, resistência, trabalhabilidade, reologia).

Sugere-se, por fim, que sejam revisitados diversos pontos estudados de hidratação e durabilidade, que fazem do $\mathrm{C}_{3} \mathrm{~A}$ um possível fator definitivo no comportamento, observando as características finais com base na forma cristalina das fases presentes na mistura. Uma atenção especial devese dar ao cimento Portland branco, visto que este possui em sua constituição elevados teores de $\mathrm{C}_{3} \mathrm{~A}$.

\section{Referências bibliográficas}

BETIOLI, A. M. Influência dos Polímeros MHEC e EVA na Hidratação e Comportamento Reológico de Pastas de Cimento Portland. 211 f. 2007. Tese (Doutorado em Engenharia Civil) - Programa de PósGraduação em Engenharia Civil, Universidade Federal de Santa Catarina, Florianópolis, 2007.

BLACK, L. et al. Hydration of Tricalcium Aluminate $\left(\mathrm{C}_{3} \mathrm{~A}\right)$ in the Presence and Absence of Gypsum: studied by Raman spectroscopy and Xray diffraction. Journal of Materials Chemistry, v. 16, p. $1263-1272,2006$.

BOIKOVA, A. I.; DOMANSKY, A. I. The Influence of $\mathrm{Na}_{2} \mathrm{O}$ on the Structure and Properties of $3 \mathrm{CaO} \cdot \mathrm{Al}_{2} \mathrm{O}_{3}$. Cement and Concrete Research, v. 7, n. 5, p. 483-492, 1977.

ESPING, O. Early age Properties of SelfCompacting Concrete: effects of fine aggregate and limestone filler. 206 f. 2007. Tese (Doutorado em Engnharia Civil). Department of Civil and Environmental Engineering Building Technology, Chalmers University of Technology, Göteborg, Suiça, 2007.

GLASSER, F. P.; MARINHO, M. B. Early Stages of the Hydration of Tricalcium Aluminate and Its Sodium-Containing Solid Solutions. British Ceramic Society, v. 35, 1984.

GOBBO, L. et al. $\mathrm{C}_{3} \mathrm{~A}$ Polymorphs Related to Industrial Clinker Alkalies Content. Cement and Concrete Research, v. 34, n. 4, p. 657-664, 2004.

HAMAD, B. S. Investigations of Chemical and Physical Properties of white Cement Concrete. Advanced Cement Based Materials, v. 2, n. 4 p. 161-167, 1995

JUENGER, M. C. G.; JENNINGS, H. M. Effects of High Alkalinity on Cement Pastes. ACI

Materials Journal, v. 98, n. 3, p. 251-255, 2001.

KIRBY, G. H.; LEWIS, J. A. Rheological Property Evolution in Concentrated Cement-Polyelectrolyte Suspensions. Journal of American Cercamic Society, v. 85, n. 12, p. 2989-2994, 2002.

\section{KIRCHHEIM, A. P. Concreto de Cimento} Portland Branco Estrutural: avaliação da carbonatação e absorção capilar. 167 f. 2003. Dissertação (Mestrado em Engenharia Civil), Escola de Engenharia, Universidade Federal do Rio Grande do Sul, Porto Alegre, 2003. 
KIRCHHEIM, A. P. Aluminatos Tricálcico Cúbico e Ortorrômbico: análise da hidratação in situ e produtos formados. 284 f. 2008. Tese (Doutorado em Engenharia Civil) - Programa de Pós-Graduação em Engenharia Civil, Universidade Federal do Rio Grande do Sul, Porto Alegre, 2008.

KIRCHHEIM, A. P. et al. Concreto Branco. In: IBRACON, São Paulo, 2005 Anais... São Paulo: IBRACON, 2005. 2 v, 1600 p.

LOCHER, F. W. Cement: principles of production and use. Düsseldorf: Verlag Bau und Technik, 2005

MASSAZZA, F.; DAIMON, M. Chemistry of Hydration of Cements and Cementitious Systems. In: INTERNATIONAL CONGRESS ON THE CHEMISTRY OF CEMENT, 9., Nova Dehli, 1992. Anais...Nova Dehli: ICCC, 1992.

MEHTA P. K. Effect of lime on hydration of pastes containing gypsum and calcium aluminates or calcium sulfoaluminate. Journal of America Ceramic Society. v. 56, n. 6, p. 315-320, 1973.

MEHTA, P. K.; MONTEIRO, P. J. M. Concrete: microstructure, properties and materials. Nova York: McGraw-Hill, 2006.

NACHBAUR, L. et al. Dynamic Mode Rheology of Cement and Tricalcium Silicate Pastes from Mixing to Setting. Cement and Concrete Research, v.31, p.183-192, 2001.

NEVILLE, A. M. Properties of Concrete. Edinburgh Gate: Harlow, 1997.

ODLER, I.; WONNEMANN, R. Effect of Alkalies on Portland Cement Hydration II: alkalies present in form of sulphates. Cement and Concrete Research, v. 13, n. 6, p. 771-777, 1983.

PAURI, M.; COLLEPARDI, M. The Effect of Ethanolamines on the $\mathrm{C}_{3} \mathrm{~A}$ Hydration in the Presence of Gypsum. Il Cemento, v. 2, p. 131140, 1987.

QUARCIONI, V. A. Influência da Cal Hidratada nas Idades Inicias da Hidratação do Cimento Portland: estudo em pasta.2008. $172 \mathrm{f}$. Tese (Doutorado em Engenharia Civil) - Escola Politécnica de Engenharia, Universidade de São Paulo, São Paulo, 2008.

RAMACHANDRAN, V. S.; BEAUDOIN, J. J. Handbook of Analytical Techniques in Concrete Science and Technology: principles, techniques, and applications. Nova York: Noyes Publications, 1999.
REGOURD, M.; GUINER, A. Cristallochimie des Constituants du Clinker de Ciment Portland.

Revue des Matériaux de Construction, v. 695, p. 201-215, 1975.

REGOURD, M. et al. Hydratation de $\mathrm{C}_{3} \mathrm{~A}$ dans des Mélanges Synthétiques et dans des Ciments Portland Industriels. In: INTERNATIONAL CONGRESS ON THE CHEMISTRY OF CEMENT, 7., 1980, Paris. Anais... Paris: ICCC, 1980. p. 477-482.

REGOURD, M. et al. Polymorphisme des Solutions Solides du Sodium dans l'Aluminate Tricalcique. Journal of Applied

Crystallography, v. 6, n. 5, p. 355-364, 1973.

SAMET, B.; SARKAR, S. L. The Influence of Calcium Sulfate Form on the Initial Hydration of Clinkers Containing Different Alkali Combinations. Cement and Concrete Research, v. 27, n. 3, p. 369-380, 1997.

SELNA, D.; MONTEIRO, P. J. M. Cathedral of Our Lady of the Angels. Concrete International, nov. 2001. p. 8.

STEPHAN, D.; WISTUBA, S. Crystal Structure Refinement and Hydration Behavior of Doped Tricalcium Aluminate. Cement and Concrete Research, v. 36, n. 11, p. 2011-2020, 2006.

SUN, Z.; VOIGT, T. et al. Rheometric and Ultrasonic Investigations of Viscoelastic Properties of Fresh Portland Cement Pastes. Cement and Concrete Research, v. 36, n. 2, p.2 78-287, 2006.

TAYLOR, H. F. W. Cement Chemistry. Londres: Academic Press, 1990.

TATTERSALL, G. H.; BANFILL, P. F. G. The Reology of Fresh Concrete. [S.1.]: Pitman Publishing, 1983. p. 49.

\section{Agradecimentos}

Ana Paula Kirchheim agradece à Capes e ao CNPq. Os autores também agradecem a valorosa colaboração de Antônio Takimi e de Victor Fernàndez-Altable, na realização dos ensaios, e a orientação da professora Maria Alba Cincotto, na análise dos resultados de calorimetria. 